\title{
The Origins of Bubbles in Laboratory Asset Markets
}

Lucy F. Ackert, Narat Charupat,

Richard Deaves, and Brian D. Kluger

Working Paper 2006-6

May 2006

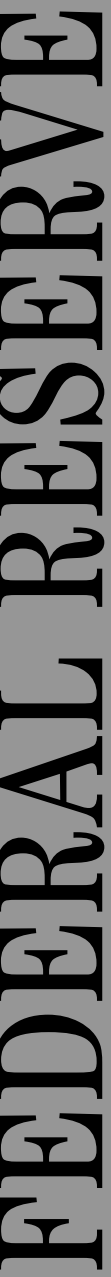




\title{
The Origins of Bubbles in Laboratory Asset Markets
}

\author{
Lucy F. Ackert, Narat Charupat, Richard Deaves, and Brian D. Kluger
}

\author{
Working Paper 2006-6 \\ May 2006
}

\begin{abstract}
In twelve sessions conducted in a typical bubble-generating experimental environment, we design a pair of assets that can detect both irrationality and speculative behavior. The specific form of irrationality we investigate is probability judgment error associated with low-probability, high-payoff outcomes. Independently, we test for speculation by comparing prices of identically paying assets in multiperiod versus single-period markets. When these tests indicate the presence of probability judgment error and speculation, bubbles are more likely to occur. This finding suggests that both factors are important bubble drivers.
\end{abstract}

JEL classification: C91, C92

Key words: bubbles, asset markets, judgment error

The authors are grateful to Bryan Church, Charles Noussair, Chuck Schnitzlein, and David Stolin as well as seminar participants at Groupe ESC Toulouse and the Cass Business School for helpful suggestions. Financial support provided by the Federal Reserve Bank of Atlanta and Social Sciences and Humanities Research Council of Canada is gratefully acknowledged. The views expressed here are the authors' and not necessarily those of the Federal Reserve Bank of Atlanta or the Federal Reserve System. Any remaining errors are the authors' responsibility.

Please address questions regarding content to Lucy F. Ackert, Department of Economics and Finance, Michael J. Coles College of Business, Kennesaw State University, 1000 Chastain Road, Kennesaw, GA 30144, 770-423-6111, lackert@kennesaw.edu, and Research Department, Federal Reserve Bank of Atlanta, 1000 Peachtree Street, N.E., Atlanta, GA 30309-4470; Narat Charupat, Michael G. DeGroote School of Business, McMaster University, 1280 Main Street West, Hamilton, Ontario, Canada L8S 4M4, 905525-9140, ext. 23987, charupat@mcmail.cis.mcmaster.ca; Richard Deaves, Michael G. DeGroote School of Business, McMaster University, 1280 Main Street West, Hamilton, Ontario, Canada L8S 4M4, deavesr@mcmaster.ca; or Brian D. Kluger, College of Business, University of Cincinnati, Cincinnati, 0H 45221-0195, brian.kluger@uc.edu.

Federal Reserve Bank of Atlanta working papers, including revised versions, are available on the Atlanta Fed's Web site at www.frbatlanta.org. Click "Publications" and then "Working Papers." Use the WebScriber Service (at www.frbatlanta.org) to receive e-mail notifications about new papers. 


\section{The ORIGINS of BUBBLES in LABORATORY ASSET MARKETS}

\section{INTRODUCTION}

Although laboratory asset markets have yielded key insights into asset pricing, some results are perplexing. ${ }^{1}$ Perhaps most striking is that in one particular, multi-period market structure, price tends to bubble above risk-neutral asset value and subsequently crash. Speculation and/or irrationality have been suggested as likely bubble ingredients. This paper further investigates bubbles by designing markets for securities whose prices can be used to detect both irrational and speculative behavior. The specific form of irrationality we investigate is probability judgment error associated with low-probability high-payoff events. We examine the price difference between two assets whose dividend distributions are nearly identical over all outcomes except for the upper tail, to see whether subjects are making this type of error. We measure speculative behavior by comparing asset prices in multi-period markets to prices in single period markets. In multi-period markets there is an opportunity to speculate across periods. Such speculation is not possible in single period markets. Our experimental results are that both speculative activity and probability judgment errors are present in sessions where bubbles occur.

We employ a market structure, first discovered by Smith, Suchanek, and Williams (1988), in which participants trade an asset that pays a dividend each period for a finite number of periods. Since the dividend-generating process and the number of periods are known to all traders, the risk-neutral value is easily computed as the expected one-period dividend times the number of trading periods remaining. Despite this transparency, Smith, Suchanek and Williams frequently observe asset price bubbles, and conclude that common knowledge about the dividend process is not sufficient to guarantee common expectations. "Each trader may be uncertain as to the behavior of others with the same information” (page 1120), and this type of uncertainty can lead to speculative bubbles. A rational trader may knowingly purchase the asset for a high price (relative to risk-neutral

\footnotetext{
${ }^{1}$ Hundreds of laboratory markets are reported in the literature. See Davis and Holt (1993) and Kagel and Roth (1995) for introductions to this literature.
} 
value) if she believes that the asset can be sold later at an even higher price to another trader. $^{2}$

Lei, Noussair and Plott (2001) further investigate this rational speculation hypothesis by conducting experiments with a similar market structure, adding a treatment where the participants are restricted to acting as either buyers or sellers of the asset. Even though this treatment entirely eliminates the opportunity to speculate, they still observe frequent bubbles. Lei, Noussair and Plott therefore conclude that the ability to speculate is not necessary for bubble formation, and that at least some of the traders are behaving irrationally in this environment.

Remaining issues concern both the nature of traders' irrationality, and the connection between some traders' irrational behavior and other traders' speculative activity. Lei, Noussair and Plott (2001) suggest that trader confusion, coupled with the fact that traders don't have anything else to occupy themselves with during the experiment, is responsible for increased trading volume, with some traders paying too much for the shares, which can then lead to bubble formation. Although this is a plausible explanation, it is unlikely to apply outside the laboratory. And yet, given financial market behavior over the last decade, many observers believe that bubbles are a real-world phenomenon.

Other experimental work indicates that many individuals exhibit bias when confronted with choices involving small probabilities and large payoffs. ${ }^{3}$ Irrationality stemming from this behavioral bias is often termed probability judgment error. We introduce the possibility that this form of irrationality will be displayed by creating an asset that has a very low probability of a large dividend payout each period. Additionally, subjects can trade a "truncated" asset. This asset pays the same large

\footnotetext{
${ }^{2}$ Much subsequent research has varied the market structure, trader characteristics and/or asset characteristics of Smith, Suchanek and Williams (1988). Some examples of market structure variations include: price limits (King, Smith, Williams and Van Boening (1993)), futures (Porter and Smith (1995)), short sales (King, Smith, Williams and Van Boening (1993), Haruvy and Noussair (2004) and Ackert, Charupat, Church and Deaves (2005a)), and a call market clearing system (Van Boening, Williams and LaMaster (1993)). Examples of trader/asset characteristic variations include: certain dividends (Porter and Smith (1995)), lottery-type assets (Ackert, Charupat, Church and Deaves (2005a)), larger-scale markets (Williams (2005)), and trader experience (King, Smith, Williams and Van Boening (1993) and Ackert and Church (2001)).

${ }^{3}$ Kahneman and Tversky (1979) document this bias using surveys. See Camerer (1995) for a survey and synthesis of related individual choice experiments.
} 
dividend with the same probability as does the "untruncated" asset, but the number of such dividend payouts is limited. Despite these conditions, the risk-neutral values of the two assets are almost always identical. The exact difference depends on the number of periods remaining, but, with the parameters used in our markets, the difference in values is generally much less than a penny. Therefore a non-trivial difference between the untruncated asset price and the truncated asset price can serve as a litmus test for the existence of probability judgment error. ${ }^{4}$ Indeed our results show a correlation between the frequency (and magnitude) of bubbles and the presence of this form of irrationality. While our findings support Lei, Noussair and Plott's (2001) conclusion that irrationality is an ingredient in bubble formation, our results also suggest that the irrationality leading to bubble formation need not be trader confusion.

Although Lei, Noussair and Plott (2001) find that bubbles occur in treatments where speculation is not possible, they do not exclude speculation as an important factor in laboratory bubbles. Their conclusion is simply that "any explanation of the bubble phenomenon, which relies on the possibility of speculation, does not provide a complete account” (page 857). They conjecture that experimental asset market bubbles evolve through stages. At the beginning, some traders behave irrationally. As the experiment progresses, other traders realize that there are irrational traders. This realization promotes speculation. Later, traders learn from experience and practice, and irrationality subsides, causing the market to crash. Their explanation suggests that bubbles are characterized by interplay between irrational and speculative behavior. Our experiment further investigates this issue.

In order to study the link between irrational behavior and potential speculation, we design a second litmus test for speculative behavior. Our subjects participate not just in a standard multi-period market, but also in several single period markets, each with more than one dividend draw. For example, a stock trading in an $n$-draw single period market has the same risk-neutral value as one trading in a multi-period market with $n$ periods remaining, when dividends are drawn according to the same distribution. The principal difference is that the latter has much greater speculative trading potential. Comparisons of asset prices across multi-period and single period markets allow us to

\footnotetext{
${ }^{4}$ As will be discussed later, other interpretations are possible.
} 
test for speculative activity. If speculation is an important ingredient in bubble formation, we expect these differences to be correlated with the frequency (and magnitude) of bubbles (in the multi-period markets). The results reported here support this view.

The remainder of the paper is organized as follows. Section II presents the experimental design. The hypotheses to be tested are set out and motivated in the next section. The experimental results are reported in Section IV, with discussion following in the next section. Section VI concludes.

\section{EXPERIMENTAL DESIGN}

\section{A. The computerized environment}

The experiment reported here was conducted using a computerized double auction market program which allows students to transact in real time over a number of market periods. $^{5}$ Traders receive initial endowments made up of cash and securities. Participants can post bids and asks, or act as price-takers by accepting the best posted bid or ask. Share and cash balances are automatically updated after transactions and dividend payments. For this experiment, traders transact one share at a time and the order book has a depth of one, which means that posted orders are erased by better bids and asks.

\section{B. Experimental assets}

Each of the 12 experimental sessions consists of three distinct markets. A multiperiod market runs over 10 trading periods. At the end of each period, assets pay a randomly determined dividend. Cash balances and asset holdings carry forward across the 10 periods. After the final dividends are paid out at the end of period 10, all assets are worthless because no further dividends are to be paid. We refer to the multi-period

\footnotetext{
${ }^{5}$ The Financial Trading System (FTS) platform, developed by S. Srivastava and J. O’Brien at Carnegie Mellon University, was used for this experiment.
} 
market as MP-10. In the other two markets, the assets trade for only a single period. In these markets, the payoffs to the assets are determined by a series of random draws. One single period market has a series of eight random draws; the other has five random draws. These single period markets are referred to as SP-8 and SP-5, respectively.

Our experiment features two types of assets in all markets. Both assets have lottery-like characteristics (though to varying degrees). ${ }^{6}$ The first type of share, labeled A, pays a dividend based on a random draw from an opaque jar containing 98 red chips and 2 black chips. If a red chip is drawn, the payout is zero, but, if a black chip is drawn, the payout is $\$ 20$. For expositional purposes only, we call this asset “untruncated." In the MP-10 market, there is a single draw at the end of each of the ten trading periods. A \$20 dividend is paid if a black chip is selected, and no dividend is paid if a red chip is selected. One could receive \$200 per share over the multi-period market, though this is a near-zero probability event. In the SP-8 market there are eight independent draws (with replacement) at the end of the one and only trading period. The payoff per share is equal to $\$ 20$ times the number of black chips drawn. Similarly, in the SP-5 market, there are five independent draws.

The second type of asset, labeled B, is similar to asset A except that the total payoff is limited as follows. Asset B pays $\$ 20$ when a black chip is drawn only if fewer than three black chips have been previously drawn. This implies that the maximum cumulative payoff from holding a share of asset $\mathrm{B}$ is $\$ 60$. The same upper bound on cumulative payout holds for the SP-5 and SP-8 versions of B. Again, for expositional purposes only, we call this asset "truncated." In addition to being intertemporally independent, dividend draws are also cross-sectionally independent. There are separate (independent) draws to determine the dividends for each type of asset.

Note that the risk-neutral values of the untruncated and truncated assets are virtually identical if one or fewer black chips has previously been drawn, but if two or more black chips have been drawn the values can diverge. Table 1 summarizes the riskneutral value of each asset by draws remaining and the number of black chips already drawn.

\footnotetext{
${ }^{6}$ Ackert, Charupat, Church and Deaves (2005a) report that traders will pay higher prices for an asset having lottery characteristics (i.e., a claim on a large, though unlikely, payoff) in a bubble market environment.
} 


\section{[INSERT TABLE 1]}

\section{Conduct of sessions}

Sessions required roughly two and one-half hours. All participants were sophomore, junior, or senior undergraduate business or economics students, and were inexperienced in that none had participated in an earlier session. On arrival, subjects were provided with a set of instructions. The experimental instructions are included in Appendix 1. They were informed that they were to be given a $\$ 15$ attendance fee, and told that their total compensation for participation would include the fee, plus profits accrued while trading in three distinct and different markets. Participants were given about 20 minutes to read through the instructions, and then the experimenters provided an extensive recap, while addressing all procedural and technical questions. After answering all questions, trading commenced. Although participants were informed that the session would include three distinct markets, they were not informed of the order in advance. $^{7}$

At the start of each market, subjects received a loan of $\$ 40$ that was returned at the end of the market. They were also endowed with two shares of both the untruncated asset (A) and the truncated asset (B), which were referred to in the experiment as stocks A and B, respectively. All trading periods lasted for five minutes. At the end of each trading period, dividends were determined by random draws. Any dividends paid were added to shareholders' balances. In addition, four items of information (per security) were announced and publicly recorded, namely the closing price (assuming a trade occurred), the dividend (which was usually zero), the expected remaining cumulative dividend, and the maximum total cumulative dividend (the maximum dividend per period multiplied by the number of periods remaining). Then about one minute was provided for subjects to consider their strategies, after which the session moved forward. At the end of each market, each subject's final cash balance was privately displayed on his or her computer screen. If a subject's total losses exceeded the $\$ 15$ attendance fee as of the

\footnotetext{
${ }^{7}$ The order of the markets within the session was randomized across sessions.
} 
end of any market, she was not allowed to participate in any remaining markets. ${ }^{8}$ Further, if, after deducting the $\$ 40$ initial cash endowment, a trader’s profit at the end of a session was negative, the attendance fee was reduced dollar for dollar. After completion of the experiment, subjects were paid in cash, with the average total compensation over all sessions being $\$ 41$, with a range of $\$ 0$ to $\$ 189$. $^{9}$

\section{HYPOTHESES}

Because the risk-neutral values of the untruncated and truncated assets in the multi-period markets are virtually identical, in the absence of irrationality associated with probability judgment error, the prices of the two assets at any point in time should also be virtually identical. This first hypothesis tests for the presence of probability judgment error. $^{10}$

Hypothesis 1: At any time, the difference between the price of the untruncated asset and the price of the truncated asset is positive. ${ }^{11}$

As argued above, irrationality may seed bubbles. If so, one would expect to see a greater gap between untruncated and truncated asset prices in bubble markets than in markets which fail to bubble. We conjecture that irrationality in one dimension (untruncated vs. truncated price differences) is associated with irrationality in another dimension (bubble formation). To investigate this conjecture, experimental markets are separated into two groups according to the existence, magnitude and duration of price bubbles. (This will be discussed in more detail in the next section). The first group of

\footnotetext{
${ }^{8}$ This bankruptcy rule is necessary so that risk is not distorted because of a subject's limited liability. In sessions 3, 7, 8, and 9, two or more subjects went bankrupt after the multi-period market.

${ }^{9}$ The experimental sessions were run at ???????? University in Canada. All dollars were Canadian.

${ }^{10}$ Although payment of dividends can cause the risk-neutral values of the truncated and untruncated assets to differ, this was not a problem in the present experiment. The expected values never diverged by more than a penny. On three occasions only (and then only for a single period) did this one-penny divergence occur (sessions 1 and 10 after a dividend was received in period 3, and session 10 again after a (second) dividend was received in period 8).

${ }^{11}$ All hypotheses to be tested are stated in their alternative forms. Naturally the null hypotheses are the complements of the alternatives. Here, for example, the null of no probability judgment error is that "the difference between the price of the untruncated asset and the truncated asset is less than or equal to zero."
} 
sessions consists of those in which the observed prices of the two assets are generally above their risk-neutral values, and the second group consists of sessions in which the observed prices of the two assets are generally close to their risk-neutral values. The second hypothesis is:

Hypothesis 2: The magnitude of the difference between the price of the untruncated asset and the price of the truncated asset is larger in bubble sessions than in no-bubble sessions.

Speculative behavior as a bubble-inducing force is also investigated here. To this end, we compare prices of assets in the multi-period markets, where speculation across periods is possible, to the corresponding prices observed in single period markets, where the scope for speculation is quite limited. If speculative activity is present, we would expect that prices of (both) assets in multi-period markets should be higher than corresponding prices in single period markets. This leads to the third hypothesis:

Hypothesis 3: Asset prices in multi-period markets are higher than corresponding asset prices in single period markets.

In the present experiment there are two single period markets in each session. One has five dividend draws (per asset) and the other has eight dividend draws (per asset). So hypothesis 3 suggests that the multi-period asset price with five (eight) periods remaining exceeds the single period asset price with five (eight) draws.

Finally, analogous to hypothesis 2, we conjecture that the presence of speculative behavior in one dimension (multi-period prices vs. single period prices) is associated with the signs of such behavior in another (bubble formation):

Hypothesis 4: The magnitude of the difference between asset prices in multi-period markets and single period markets is greater in bubble markets than in no-bubble markets. 


\section{EXPERIMENTAL RESULTS}

Table 2 contains median prices for both assets over all periods during the 12 experimental sessions. ${ }^{12}$ Additionally, median transaction prices for the multi-period markets are graphed in Figures 1 and 2. Notice that Figure 1 contains sessions 1, 3, 6, 7, 10, and 11; while Figure 2 contains sessions 2, 4, 5, 8, 9, and 12. Below we will dichotomize multi-period markets into "bubble" markets (B) and "no-bubble" markets (NB) using several categorization techniques. As will be described, one of the techniques categorizes sessions $1,3,6,7,10$, and 11 as B markets, and the remaining sessions as NB markets.

\section{[INSERT TABLE 2]}

[INSERT FIGURE 1]

[INSERT FIGURE 2]

Figure 1 shows that, for some sessions, bubble and crash patterns occurred somewhat similar to the results widely reported in previous studies. However, Figure 2 shows that in other sessions prices of both assets were close to their risk-neutral values throughout the ten periods of the multi-period markets.

\section{A. Test of Hypothesis 1}

We test Hypothesis 1 using prices observed in the multi-period markets. Table 3 reports differences between median prices of the untruncated asset and the truncated asset in all ten periods of all 12 sessions. Differences are reported in both absolute dollar and percentage (relative to the untruncated asset price) terms. Table 3 also reports the pvalues corresponding to a one-tailed Wilcoxon Signed Rank test with the null hypothesis that the price difference is zero (and the alternative that the untruncated price is greater than the truncated price.

\footnotetext{
${ }^{12}$ Empirical tests are in terms of these median prices. Nevertheless results are robust to the use of mean prices. From this point on, the term "prices" will refer to median prices. In the rare cases when no transaction occurred, the mid-point of the terminal bid-ask spread is used.
} 


\section{[INSERT TABLE 3]}

Consider first, the final three periods. In the majority of our sessions, there was no dividend paid in the first seven periods. If so, there is no difference between the untruncated and the truncated assets in the sense that the restriction on dividends cannot bind. The truncated asset cannot pay more than three times. But with three periods remaining, the untruncated cannot pay more than three times either. Therefore we would not expect to see a price difference in periods 8 through 10 . The data support this. The hypothesis of no difference between the untruncated and truncated cannot be rejected (Wilcoxon Signed Rank probabilities are all .500 or higher) for periods eight, nine, or ten.

In contrast, we report that the untruncated asset price is higher than the truncated for periods one to seven. A Wilcoxon test that the untruncated price over the first seven periods (averaging over the medians for each period) equals the truncated price is rejected with $\mathrm{p}=.183$ for dollar differences and $\mathrm{p}=.046$ for percentage differences. However, Table three contains datapoint in session 9, period 2 where the percentage difference was $1500 \%$, a value several orders of magnitude higher than any other percentage difference. This may be the result of a typing error made by one of the subjects. If this data point is not included in the average of the price differences over periods 1-7, the Wilcoxon Signed ranks are as reported above. Including the value changes the p values to .009 for the null that the percentage differences are zero, and .051 for the null that the dollar differences are zero. The data corresponding to the $1500 \%$ has been excluded in the remainder of the analysis.

Accordingly, the data provide some support for Hypothesis 1 . The price of the untruncated asset is generally higher than the price of the truncated asset. Further, the price differences are generally declining over the course of the experiment. This pattern is consistent with the idea that mispricing is more likely when the untruncated asset has more dividend draws remaining. From this we can infer that participants were susceptible to irrationality associated with probability judgment error. 


\section{B. Categorizing markets as bubble or no-bubble markets}

In order to test the second hypothesis, we must first separate sessions into two groups: those with B multi-period markets and those with NB multi-period markets. We use as criteria the four multi-period market summary statistics shown in Table $4 .{ }^{14}$ The first criterion is the "number of positive periods," which is the number of periods in each session in which the median prices of the two assets exceed their risk-neutral values. A large number of positive periods indicates that trades generally and persistently occur at high prices. The second criterion is the "percent of positive trades," which is the percentage of transactions at prices higher than risk-neutral values. Depending on the distribution of transactions across the ten periods, this criterion may or may not lead to the same classification as the first criterion. The next criterion is the "average price deviation," which is the average across periods of the differences between price and riskneutral value in each period. Again, a high value implies that trades generally and persistently occur at too high prices. The final criterion is a variant of the latter. Since, arguably, price deviations should be normalized by the relevant risk-neutral value, the last criterion is the "average scaled price deviation."15

\section{[INSERT TABLE 4]}

As a cursory inspection of Table 4 indicates, the first and second criteria lead to the same conclusion, which is to classify sessions 1, 3, 6, 7, 10 and 11 as B sessions, and the rest as NB sessions. This classification we call Dichotomization A. Figures 1 and 2 reflect this categorization. The third criterion, however, yields a slightly different result. The average price deviation is obviously high in sessions 1, 6, 7 and 10, and low in sessions 2, 4, 5, 8 and 12. Nevertheless, the other three sessions, 3, 9 and 11, are not clear-cut, and are thus dropped. This classification we call Dichotomization B. Next, when the average price deviation is normalized, the only change from Dichotomization B

\footnotetext{
${ }^{14}$ One could also consider single period markets for the purpose of characterizing sessions, but, conventionally, when one speaks of a bubble, one means a case where prices are consistently above riskneutral value.

${ }^{15}$ Similar bubble measures are used in other papers studying the phenomenon (e.g., Smith, Suchanek and Williams (1988) and Ackert, Charupat, Church and Deaves (2005a)). The reality is that there is no perfect measure, which is why we use several dichotomizations.
} 
is that session 9 moves from the neither group into the no-bubble group. This classification we call Dichotomization C.

\section{[INSERT TABLE 5]}

These dichotomizations are summarized in Table 5.

\section{Test of Hypothesis 2}

The second hypothesis is tested using the three dichotomizations detailed above. Recall that the hypothesis to be tested is that the magnitude of the difference between the price of the untruncated asset and the price of the truncated asset is larger in B sessions than in NB sessions. In other words, irrationality with regard to the pricing of lottery-like assets is more likely to be associated with asset pricing bubbles.

\section{[INSERT TABLE 6]}

Table 6 reports the average difference (in periods 1 through 7) between the untruncated and truncated asset prices across sessions classified as either bubble or nobubble. The analysis is repeated for the three dichotomizations described above. The average price difference in both dollars and on a percentage basis is larger for bubble sessions than for non-bubble sessions regardless of the dichotomization used. The null hypothesis that the difference between the untruncated and truncated asset prices is the same in bubble markets as in no-bubble markets is rejected using a pooled t-test with a five percent significance level for both dollar and percentage differences for all three dichotomizations. Our results support hypothesis two, providing evidence of correlation between the existence of price bubbles and the presence of irrationality associated with probability judgment error.

\section{Test of Hypothesis 3}

We now turn to an investigation of whether prices in multi-period markets (with eight or five periods remaining) are higher than prices in corresponding single period 
markets (with eight or five dividend draws). The multi-period markets are fundamentally different from the single period markets because speculation across periods is possible. A trader can purchase or sell shares in earlier periods and potentially repurchase or resell them in subsequent periods. The single period markets do not allow speculation across periods simply because there are no subsequent periods. ${ }^{16}$ Nevertheless, the risk-neutral values of the assets in $n$-draw single period markets are equivalent to those in corresponding multi-period markets with $n$ periods remaining. This is because the number of drawings and the probability of a dividend payoff per period is the same in both cases. Observed differences in asset prices are likely due to speculative activity in the multi-period markets. These price differences are shown in Table 7.

\section{[INSERT TABLE 7]}

The average MP price is greater than the corresponding SP price in all cases, supporting hypothesis three, and indicative of speculative activity in the MP markets. Further, Table 7 shows that the price difference (MP-SP) is larger when there are 8 draws remaining than when there are 5 draws remaining. This is also consistent with the speculative explanation because it is reasonable to suppose that there is more scope for successful speculation when there are more periods remaining.

\section{E. Test of Hypothesis 4}

Hypothesis 4 also concerns the price differences between the MP market and the corresponding SP market. Table 8 compares the average MP-SP price for each asset in bubble sessions to corresponding values in no-bubble sessions.

\section{[INSERT TABLE 8]}

Average MP-SP prices are all much greater in bubble sessions, regardless of the dichotomization used. Further, the average MP-SP price difference is greater in bubble

\footnotetext{
${ }^{16}$ Admittedly, in single period markets limited speculation is possible within periods.
} 
markets when the asset has eight dividend draws remaining. These results are again consistent with the explanation that speculative activity is a factor in bubble sessions.

\section{V.DISCUSSION}

Before proceeding to a general discussion of the results, two salient issues must be addressed. First, why are there at most six out of 12 markets that bubble and crash? Second, can we be sure that the irrationality being detected is associated with probability judgment error? After discussing these issues we consider what our results say about an appropriate theory of bubbles.

\section{A. Relative infrequency of bubbles}

We report bubbles in no more than half of the sessions we conduct. This is less than the frequency reported in similar experiments. One reason for the discrepancy may be the difference in the length of our multi-period markets. In our experiments, there were ten periods, but Smith, Suchanek and Williams (1988) mostly use 15 periods. Porter and Smith (1995) use 15 periods as well, and Lei, Noussair and Plott (2001) use 12-, 15and 18-period markets. Presumably, backward induction is easier in a ten-period setting. Since the ability to backwards induct will probably help participants achieve rational pricing, markets with fewer periods may be less likely to have bubbles.

A second possible reason for bubble scarcity may be learning. Previously cited work documents that experimental experience in the same environment moderates price bubbles. In our experiments, subjects may be indirectly learning from the single period markets if they are run prior to the multi-period markets. Each experimental session consists of two single period markets and a multi-period market, SP-5, SP-8 and MP-10. Our experimental design uses a randomized block to sequence the order of the markets. The order in which the markets were conducted is shown in Table 2. We report (at most) six instances of bubbles (sessions 1, 3, 6, 7, 10 and 11). In sessions 3 and 10, the MP-10 was conducted first; in sessions 1 and 7, the MP-10 was second; and in sessions 6 and 11, the MP-10 was third. Based on this observation, there is no correlation between the 
absence or presence of a bubble and the order in which the three markets were conducted. Learning does not appear to explain why price bubbles do not form in fully half of our sessions.

Finally, Caginalp, Porter, and Smith (1998, 2000a, 2000b, 2001) suggest that price bubbles may increase as the ratio of available cash to available shares increases. In our experiments, the subjects were given $\$ 40$ that they had to return at the end of the session. In addition, they were told that that they would be excused from their session if their cash balance dropped below their guaranteed attendance fee of $\$ 15$ as of the end of each market. It is possible that the low starting cash and the bankruptcy restriction limited the magnitude of the price bubbles in our experiments.

\section{B. Probability judgment error}

We cannot be sure that the observed irrationality, inherent both in bubble formation and in the gap between untruncated and truncated asset prices, stems from probability judgment error and not from another behavioral bias. Indeed there are several non-mutually exclusive plausible hypotheses that might account for our results. One such possibility is known as the house money effect (Thaler and Johnson (1990)). After a successful dividend payout occurs, asset prices (if already high) may depart further from risk-neutral value. The reason is that, if subjects view wealth earned during the experiment differently than wealth earned from other means (e.g., wages), then their riskreturn decisions may differ depending on which sort of wealth is at risk. Thaler and Ziemba (1988) refer to such mental accounts for an explanation of some racetrack betting anomalies. Additionally, Ackert, Charupat, Church and Deaves (2005b) find evidence of this effect in an experimental setting. ${ }^{17}$

Examination of our results shows that bubbles occurred more often in the multiperiod markets in sessions where there was a successful dividend draw in either a prior single period market and/or in an early period of the multi-period market. Again, under Dichotomization A, we classify six sessions as B markets. In four of these $(1,6,7$ and 10), there was a dividend in a prior single period market or a dividend before the third

17 In addition, if subjects (incorrectly) view successive dividend draws as dependent, they believe that the probability of another dividend is higher after a recent payout. The outcome in this case cannot be distinguished from that arising with a house money effect. 
period of the multi-period market, or both. On the other hand, in four of the six NB sessions there was no dividend payout in either the multi-period market or in a prior single period market. Session 5 paid a dividend only after period ten of the multi-period market, which clearly could not have influenced prices since the successful draw took place after all trading. Session 12, the final NB session, had a dividend payout in an earlier single period market. Although this session is classified as an NB session, prices are not as close to risk-neutral value as in the other NB sessions. Though we do not formally test for a house money effect here, our results indicate that it may play a role in explaining the observed behavior.

It is also possible that non-standard preferences may explain the difference between untruncated and truncated asset prices in our experiment. Barberis and Huang (2004) show that under cumulative prospect theory (Tversky and Kahneman (1992)), investors can overweight the tails of a payoff distribution, causing them to overvalue assets whose payoffs are positively skewed. The more positively skewed a payoff is, the higher is the value investors will assign to it. In our experiment, subjects may have paid a premium for the untruncated asset because its payoffs are more positively skewed.

\section{What are the origins of bubbles?}

Next we turn to the question of what facilitates bubble formation, and to what extent individual irrationality or bias aggregates into market outcomes. Speculative behavior seems to be a force behind experimental bubbles, and we find evidence consistent with this. Yet speculation is not essential. Lei, Noussair and Plott (2001) show that bubbles can form even when a trader cannot profit from speculation by undertaking round-trip transactions. While bubbles can occur without the opportunity to speculate, it seems that subject irrationality - whatever its form - is a key ingredient in bubble formation.

Lei, Noussair and Plott (2001) and Lei and Vesely (2004) suggest that subject confusion may be the source of the irrationality at the root of laboratory bubbles. Bubbles may be found in markets with decision errors due to subject confusion about the instructions, the nature of the market, or because there is no alternative activity. While not contradicting this, our results add to the experimental literature by showing that 
another sort of irrationality may as well be linked to bubbles. Bubbles may also be found in markets with decision errors due to behavioral biases such as probability judgment error.

Linking behavioral bias and bubbles raises additional issues regarding subject heterogeneity and interactions. In some circumstances, individual biases seem to aggregate into markets prices, but in other circumstances this does not occur. Gneezy, Kapteyn and Potters (2003; page 823) investigate myopic loss aversion as an explanation of the equity premium puzzle and argue that "individual violations of standard expected utility theory do not necessarily imply that market outcomes will violate expected utility theory." Yet they document myopic loss aversion at the level of the market. Kluger and Wyatt (2004) investigate probability judgment error via the Monty Hall problem, and find that the bias disappears in markets even if a minority of the traders exhibit immunity to this bias as measured by individual-level tests. Extending this to irrationality discovered in laboratory bubble markets, it is likely that the formation and magnitude of bubbles is sensitive to both the mix of rational and irrational traders and their interaction. Unfortunately, the nature of our design does not allow us to make conclusions about this issue. Nevertheless, we establish that aggregate irrationality measured in one dimension (probability judgment error) is associated with aggregate irrationality measured in another (bubble formation). Looking ahead, future research might be designed to relate individual-level irrationality to bubble formation.

\section{SUMMARY}

In some, but not all, of the twelve sessions conducted for this experiment, we observe a bubble pattern in the prices of both assets. Bubbles occur more frequently in sessions where there is a large difference between the prices of the untruncated and the truncated assets. This is consistent with irrationality associated with probability judgment error. Additionally, our paper provides evidence that speculative activity, as well as irrationality, is present in bubble markets. Such effects can be identified by comparing prices in single period markets to corresponding prices in multi-period markets. When bubbles occur, single period prices tend to be lower than corresponding 
multi-period market prices. Therefore, our results also support the view that speculation is an ingredient of laboratory asset price bubbles. 


\section{REFERENCES}

Ackert, Lucy F. and Bryan K. Church, 2001, "The Effects of Subject Pool and Design Experience on Rationality in Experimental Asset Markets," Journal of Psychology and Financial Markets, 2(1), 6-28.

Ackert, Lucy F., Charupat, Narat, Church, Bryan K. and Richard Deaves, 2005a, "Margin, Short Selling, and Lotteries in Experimental Asset Markets," Forthcoming in the Southern Economic Journal.

Ackert, Lucy F., Charupat, Narat, Church, Bryan K. and Richard Deaves, 2005b "An Experimental Examination of the House Money Effect in a Multi-period Setting," Forthcoming in Experimental Economics.

Barberis, Nicholas and Ming Huang, 2004, "Stocks as Lotteries: The Implications of Probability Weighting for Security Prices,” Working Paper.

Caginalp, Gunduz, David Porter, and Vernon Smith, 1998, "Initial cash/asset ratio and asset prices: An Experimental Study," Proceedings of the National Academy of Sciences, 95, January, 756-761.

Caginalp, Gunduz, David Porter, and Vernon Smith, 2000a, "Momentum and Overreaction in Experimental Asset Markets," International Journal of Industrial Organization, 18, 187204.

Caginalp, Gunduz, David Porter, and Vernon Smith, 2000b, "Overreactions, Momentum, Liquidity, and Price Bubbles in Laboratory and Field Asset Markets," Journal of Psychology and Financial Markets, 1(1), 24-48.

Caginalp, Gunduz, David Porter, and Vernon Smith, 2001, "Financial Bubbles: Excess Cash, Momentum, and Incomplete Information,” Journal of Psychology and Financial Markets, 2(2), 80-99.

Camerer, Colin, 1995, “Individual Decision Making,” in John Kagel and Alvin Roth, eds. The Handbook of Experimental Economics, Princeton: Princeton University Press, pp. 587703.

Davis, Douglas D. and Charles A. Holt, 1993, Experimental Economics, Princeton University Press, Princeton, New Jersey.

Gneezy, U., A. Kapteyn and J. Potters, 2003, "Evaluation periods and asset prices in a market experiment,” Journal of Finance 58, 821-37.

Haruvy, Ernan and Charles Noussair, 2004, "The Effect of Short Selling on Bubbles and Crashes in Experimental Spot Asset Markets," University of Texas at Dallas and Emory University Working Paper.

Kagel, John. H. and Alvin E. Roth (editors), 1995, The Handbook of Experimental Economics, Princeton University Press, Princeton, New Jersey. 
Kahneman, Daniel, and Amos Tversky, 1979, "Prospect Theory: An Analysis of Decision Under Risk,” Econometrica, 47(2), March 1979, 263-291.

King, Ronald R., Smith, Vernon L., Williams, Arlington W., and Mark Van Boening, 1993, “The Robustness of Bubbles and Crashes in Experimental Stock Markets”, in R. H. Day and P. Chen, eds., Nonlinear Dynamics and Evolutionary Economics, New York: Oxford University Press, pp. 183-200.

Kluger, B. D., and S. B. Wyatt, 2004, "Are judgment errors reflected in market prices and allocations? Experimental evidence based on the Monty Hall problem," Journal of Finance 59: 969-97.

Lei, Vivian, Charles Noussair, and Charles Plott, 2001, "Nonspeculative Bubbles in Experimental Asset Markets: Lack of Common Knowledge of Rationality vs. Actual Irrationality," Econometrica, July, 69(4), 831-859.

Lei, Vivian, and Filip Vesely, 2004, "Market Efficiency: Evidence from a No-Bubble Asset Market Experiment,” University of Wisconsin-Milwaukee Working Paper.

Porter, David and Vernon Smith, 1995, "Futures Contracting and Dividend Uncertainty in Experimental Asset Markets,” Journal of Business, October, 68(4), 509-541.

Smith, Vernon L., Gerry L. Suchanek, and Arlington W. Williams, 1988, "Bubbles, Crashes, and Endogenous Expectations in Experimental Spot Asset Markets," Econometrica, September, 56(5), 1119-1151.

Thaler, Richard and Eric Johnson, 1990, "Gambling with the House Money and Trying to Break Even: The Effects of Prior Outcomes on Risky Choice,” Management Science 36, 64360.

Thaler, Richard H. and William T. Ziemba, 1988, “Anomalies: Pari-mutuel Betting Markets: Racetracks and Lotteries,” Journal of Economic Perspectives, Spring, 2(2), 161-174.

Tversky, Amos and Daniel Kahneman, 1992, “Advances in Prospect Theory: Cumulative Representation of Uncertainty,” Journal of Risk and Uncertainty, 5, 297-323.

Van Boening, Mark V., Arlington W. Williams and Shawn Lamaster, 1993, "Price bubbles and crashes in experimental call markets,” Economics Letters 41: 179-185.

Williams, Arlington W., 2005, Price bubbles in large financial asset markets,” in Plott and Smith (eds.) Handbook of Experimental Economic Results, Forthcoming. 


\section{TABLE 1: Asset Liquidation Values}

Independent draws determine the dividend for two assets where the payout is $\$ 20$ with probability 0.02 , and zero otherwise. The truncated asset has a maximum payout of $\$ 60$. The table shows the risk-neutral value of each asset across the number of dividend draws remaining. The risk-neutral value for the untruncated is the expected payout $(\$ 20 * 0.02=\$ 0.40)$ multiplied by the number of draws remaining. The truncated asset's risk-neutral value is computed conditional on the number of previous \$20 draws.

Panel A: Expected total dividends for each asset

\begin{tabular}{cccccc}
\hline & & \multicolumn{5}{c}{$\begin{array}{c}\text { Truncated Asset } \\
\text { Draws }\end{array}$} & $\begin{array}{c}\text { Untruncated } \\
\text { Remaining }\end{array}$ & Asset & $(0)$ & $(1)$ & (2) & (3 or more) \\
\cline { 3 - 6 } & $\$ 4.00$ & $\$ 4.00$ & & & \\
\hline 10 & $\$ 3.60$ & $\$ 3.60$ & $\$ 3.59$ & & \\
\hline 9 & $\$ 3.20$ & $\$ 3.20$ & $\$ 3.19$ & $\$ 2.98$ & \\
\hline 8 & $\$ 2.80$ & $\$ 2.80$ & $\$ 2.79$ & $\$ 2.64$ & $\$ 0$ \\
\hline 7 & $\$ 2.40$ & $\$ 2.40$ & $\$ 2.40$ & $\$ 2.28$ & $\$ 0$ \\
\hline 6 & $\$ 2.00$ & $\$ 2.00$ & $\$ 2.00$ & $\$ 1.92$ & $\$ 0$ \\
\hline 5 & $\$ 1.60$ & $\$ 1.60$ & $\$ 1.60$ & $\$ 1.55$ & $\$ 0$ \\
\hline 4 & $\$ 1.20$ & $\$ 1.20$ & $\$ 1.20$ & $\$ 1.18$ & $\$ 0$ \\
\hline 3 & $\$ 0.80$ & $\$ 0.80$ & $\$ 0.80$ & $\$ 0.79$ & $\$ 0$ \\
\hline 2 & $\$ 0.40$ & $\$ 0.40$ & $\$ 0.40$ & $\$ 0.40$ & $\$ 0$ \\
\hline 1 & & & & &
\end{tabular}

Panel B: Probability distributions for total dividends for each type of asset with eight draws remaining and five draws

\begin{tabular}{ccccc}
\hline $\begin{array}{c}\text { Total } \\
\text { Dividend }\end{array}$ & $\begin{array}{c}\text { 8 Draws } \\
\text { Untruncated } \\
\text { Asset }\end{array}$ & $\begin{array}{c}\text { 8 Draws } \\
\text { Truncated } \\
\text { Asset }\end{array}$ & $\begin{array}{c}\text { 5 Draws } \\
\text { Untruncated } \\
\text { Asset }\end{array}$ & $\begin{array}{c}5 \text { Draws } \\
\text { Truncated } \\
\text { Asset }\end{array}$ \\
\hline 0 & 0.850763023 & 0.85076302 & 0.903920797 & 0.903920797 \\
\hline$\$ 20$ & 0.138900085 & 0.138900085 & 0.092236816 & 0.092236816 \\
\hline$\$ 40$ & 0.009921435 & 0.009921435 & 0.003764768 & 0.003764768 \\
\hline$\$ 60$ & 0.000404957 & 0.000415457 & 0.000076832 & 0.000077619 \\
\hline$\$ 80$ & 0.000010331 & & 0.000000784 & \\
\hline$\$ 100$ & 0.000000169 & & 0.000000003 & \\
\hline$\$ 120$ & 0.000000002 & & & \\
\hline$\$ 140$ & $<0.000000001$ & & & \\
\hline$\$ 160$ & $<0.000000001$ & & &
\end{tabular}




\section{TABLE 2: Median Asset Prices}

The table reports median asset prices for all markets in all sessions. The midpoint of the bid-ask spread is reported for periods with no transactions. An asterisk signifies that the asset paid a \$20 dividend at the end of the corresponding period. A pound sign signifies that there was no trading in the relevant period, so price is expressed as the midpoint in the bid-ask spread. The markets are reported in the same order as they were administered.

\begin{tabular}{|c|c|c|c|c|c|c|c|c|c|c|c|}
\hline Session & $\begin{array}{l}\text { Draws Remaining } \\
\text { Expected Value }\end{array}$ & $\begin{array}{c}10 \\
4.00 \\
\end{array}$ & $\begin{array}{c}9 \\
3.60 \\
\end{array}$ & $\begin{array}{c}8 \\
3.20 \\
\end{array}$ & $\begin{array}{c}7 \\
2.80 \\
\end{array}$ & $\begin{array}{c}6 \\
2.40 \\
\end{array}$ & $\begin{array}{c}5 \\
2.00 \\
\end{array}$ & $\begin{array}{c}4 \\
1.60 \\
\end{array}$ & $\begin{array}{c}3 \\
1.20 \\
\end{array}$ & $\begin{array}{c}2 \\
0.80 \\
\end{array}$ & $\begin{array}{c}1 \\
0.40 \\
\end{array}$ \\
\hline 1 & Untruncated SP-5 & & & & & & $8.50 *$ & & & & \\
\hline 1 & Truncated SP-5 & & & & & & 8.50 & & & & \\
\hline 1 & Truncated MP-10 & 7.50 & 9.00 & $5.20 *$ & 7.98 & 7.50 & 7.30 & 6.75 & 6.50 & 4.00 & 1.50 \\
\hline 1 & Untruncated SP-8 & & & 7.75 & & & & & & & \\
\hline 1 & Truncated SP-8 & & & 5.00 & & & & & & & \\
\hline 2 & Untruncated SP-8 & & & 2.87 & & & & & & & \\
\hline 2 & Truncated SP-8 & & & 2.60 & & & & & & & \\
\hline 2 & Untruncated MP-10 & 2.20 & 2.38 & 2.38 & 2.28 & 1.60 & 1.00 & 1.00 & 1.11 & 1.30 & 1.60 \\
\hline 2 & Truncated MP-10 & 2.00 & 2.36 & 2.40 & 2.30 & 1.85 & 1.00 & 0.95 & 1.20 & 1.50 & 1.98\# \\
\hline 2 & Untruncated SP-5 & & & & & & 0.21 & & & & \\
\hline 2 & Truncated SP-5 & & & & & & 0.27 & & & & \\
\hline 3 & Untruncated MP-10 & 5.00 & 6.60 & 7.00 & 4.00 & 2.45 & 2.60 & 3.00 & 2.30 & 1.50 & 0.48 \\
\hline 3 & Truncated MP-10 & 3.10 & 7.85 & 4.00 & 3.50 & 2.75 & 2.70 & 2.71 & 3.00 & 1.55 & 0.50 \\
\hline 3 & Untruncated SP-5 & & & & & & 1.25 & & & & \\
\hline 3 & Truncated SP-8 & & & 0.60 & & & & & & & \\
\hline 4 & Untruncated MP-10 & 4.50 & 3.60 & 2.98 & 2.57 & 2.30 & 1.35 & 0.32 & 0.45 & 0.31 & 0.18 \\
\hline 4 & Truncated MP-10 & 4.25 & 3.25 & 2.75 & 2.56 & 2.20 & 1.28 & 0.40 & 0.40 & 0.35 & 0.18 \\
\hline 4 & Untruncated SP-8 & & & 0.33 & & & & & & & \\
\hline 4 & Truncated SP-8 & & & 0.30 & & & & & & & \\
\hline 4 & Untruncated SP-5 & & & & & & 0.31 & & & & \\
\hline 4 & Truncated SP-5 & & & & & & 0.30 & & & & \\
\hline 5 & Untruncated SP-8 & & & 3.50 & & & & & & & \\
\hline 5 & Truncated SP-8 & & & 3.50 & & & & & & & \\
\hline 5 & Untruncated SP-5 & & & & & & 1.67 & & & & \\
\hline 5 & Truncated SP-5 & & & & & & 2.00 & & & & \\
\hline 5 & Untruncated MP-10 & 2.00 & 1.75 & 1.65 & 1.59 & 1.50 & 1.46 & 1.35 & 1.20 & 0.65 & $0.16^{*}$ \\
\hline 5 & Truncated MP-10 & 1.90 & 1.40 & 1.50 & 1.45 & $1.55 \#$ & 1.35 & 1.20 & 0.95 & 0.50 & 0.29 \\
\hline
\end{tabular}


TABLE 2 Continued

\begin{tabular}{|c|c|c|c|c|c|c|c|c|c|c|c|}
\hline Session & $\begin{array}{l}\text { Draws Remaining } \\
\text { Expected Value }\end{array}$ & $\begin{array}{c}10 \\
4.00\end{array}$ & $\begin{array}{c}9 \\
3.60\end{array}$ & $\begin{array}{c}8 \\
3.20 \\
\end{array}$ & $\begin{array}{c}7 \\
2.80 \\
\end{array}$ & $\begin{array}{c}6 \\
2.40 \\
\end{array}$ & $\begin{array}{c}5 \\
2.00\end{array}$ & $\begin{array}{c}4 \\
1.60 \\
\end{array}$ & $\begin{array}{c}3 \\
1.20\end{array}$ & $\begin{array}{c}2 \\
0.80 \\
\end{array}$ & $\begin{array}{c}1 \\
0.40\end{array}$ \\
\hline 6 & Untruncated SP-5 & & & & & & 4.00 & & & & \\
\hline 6 & Truncated SP-5 & & & & & & $5.00 *$ & & & & \\
\hline 6 & Truncated SP-8 & & & 5.00 & & & & & & & \\
\hline 6 & Untruncated MP-10 & 5.10 & 5.20 & 4.98 & 4.85 & 4.95 & 4.85 & 4.98 & 4.55 & 3.49 & 0.56 \\
\hline 6 & Truncated MP-10 & 5.05 & 5.13 & 4.88 & 4.88 & 4.90 & 4.85 & 4.79 & 4.55 & 2.31 & 0.60 \\
\hline 7 & Untruncated SP-5 & & & & & & 6.00 & & & & \\
\hline 7 & Truncated SP-5 & & & & & & 8.00 & & & & \\
\hline 7 & Untruncated MP-10 & 6.90 & 7.00 & 7.55 & 7.05 & 6.10 & 5.10 & 5.32 & 5.10 & 2.67 & 0.32 \\
\hline 7 & Truncated MP-10 & 6.05 & 5.65 & 6.60 & 6.50 & 6.10 & 6.00 & 5.40 & 5.20 & 3.20 & 0.23 \\
\hline 7 & Untruncated SP-8 & & & 1.15 & & & & & & & \\
\hline 7 & Truncated SP-8 & & & 1.00 & & & & & & & \\
\hline 8 & Untruncated SP-8 & & & 3.10 & & & & & & & \\
\hline 8 & Truncated SP-8 & & & 4.20 & & & & & & & \\
\hline 8 & Untruncated MP-10 & 4.00 & 3.70 & 3.04 & 2.81 & 2.21 & 2.00 & 1.25 & 1.18 & 1.11 & 0.78 \\
\hline 8 & Untruncated SP-5 & & & & & & 0.58 & & & & \\
\hline 8 & Truncated SP-5 & & & & & & 0.25 & & & & \\
\hline 9 & Untruncated MP-10 & 20.00 & 8.00 & 3.00 & 2.00 & 1.45 & 0.93 & 0.73 & 0.59 & 0.30 & 0.19 \\
\hline 9 & Truncated MP-10 & 24.00 & 0.50 & 1.75 & 2.80 & 1.40 & 0.85 & 1.38 & 0.70 & $0.48 \#$ & 0.24 \\
\hline 9 & Untruncated SP-5 & & & & & & 0.17 & & & & \\
\hline 9 & Truncated SP-5 & & & & & & 0.20 & & & & \\
\hline 9 & Untruncated SP-8 & & & 0.26 & & & & & & & \\
\hline 9 & Truncated SP-8 & & & 0.25 & & & & & & & \\
\hline 10 & Untruncated MP-10 & 22.70 & 18.00 & 11.00 & 12.00 & 13.50 & 11.50 & 10.01 & 4.95\# & 2.10 & 1.20 \\
\hline 10 & Truncated MP-10 & 19.99 & 16.50 & $12.00 *$ & 6.50 & 10.99 & 11.00 & 10.01 & $6.20 *$ & 2.30 & 1.23 \\
\hline 10 & Untruncated SP-8 & & & 2.97 & & & & & & & \\
\hline 10 & Truncated SP-8 & & & 3.95 & & & & & & & \\
\hline 10 & Untruncated SP-5 & & & & & & 1.00 & & & & \\
\hline 10 & Truncated SP-5 & & & & & & 1.09 & & & & \\
\hline
\end{tabular}


TABLE 2 Continued

\begin{tabular}{|c|c|c|c|c|c|c|c|c|c|c|c|}
\hline Session & $\begin{array}{l}\text { Draws Remaining } \\
\text { Expected Value }\end{array}$ & $\begin{array}{c}10 \\
4.00\end{array}$ & $\begin{array}{c}9 \\
3.60 \\
\end{array}$ & $\begin{array}{c}8 \\
3.20 \\
\end{array}$ & $\begin{array}{c}7 \\
2.80\end{array}$ & $\begin{array}{c}6 \\
2.40 \\
\end{array}$ & $\begin{array}{c}5 \\
2.00 \\
\end{array}$ & $\begin{array}{c}4 \\
1.60 \\
\end{array}$ & $\begin{array}{c}3 \\
1.20\end{array}$ & $\begin{array}{c}2 \\
0.80\end{array}$ & $\begin{array}{c}1 \\
0.40\end{array}$ \\
\hline 11 & Untruncated SP-8 & & & 10.00 & & & & & & & \\
\hline 11 & Truncated SP-8 & & & $4.50^{*}$ & & & & & & & \\
\hline 11 & Untruncated SP-5 & & & & & & 6.00 & & & & \\
\hline 11 & Truncated SP-5 & & & & & & 5.50 & & & & \\
\hline 11 & Untruncated MP-10 & 4.35 & 3.62 & 3.98 & 4.00 & 4.24 & 2.00 & 3.70 & 3.35 & 1.68 & 1.00 \\
\hline 11 & Truncated MP-10 & 7.00 & 4.10 & 3.78 & 3.97 & 4.00 & 3.92 & 3.40 & 3.00 & 1.61 & 1.00 \\
\hline 12 & Untruncated SP-5 & & & & & & 4.25 & & & & \\
\hline 12 & Truncated SP-5 & & & & & & 3.75 & & & & \\
\hline 12 & Untruncated SP-8 & & & $1.25^{*}$ & & & & & & & \\
\hline 12 & Truncated SP-8 & & & 1.10 & & & & & & & \\
\hline 12 & Untruncated MP-10 & 1.88 & 2.60 & 1.95 & 1.56 & 1.64 & 2.82 & 1.59 & 1.51 & 1.25 & 0.55 \\
\hline 12 & Truncated MP-10 & 5.00 & 2.63 & 1.45 & 1.50 & 1.62 & 1.63 & 1.60 & 1.61 & 1.28 & 0.45 \\
\hline
\end{tabular}




\section{TABLE 3: Untruncated and Truncated Asset Price Differences}

Panel A shows the difference between untruncated (asset A) and truncated (asset B) asset prices for all periods (1-10) over all 12 multi-period markets. Panel B shows the percentage differences. Median prices are used for both assets. Averages of the median price differences are reported both across sessions, and across the first seven periods. When no trading occurs, the average of the terminal bid and ask is used. The p-value corresponds to a one-tailed Wilcoxon Signed-Rank test with the null hypothesis that the Untruncated Price equals the Truncated Price.

Panel A: Dollar difference between median asset prices: Untruncated Price - Truncated Price

\begin{tabular}{|c|c|c|c|c|c|c|c|c|c|c|c|}
\hline Session & Period 1 & Period 2 & Period 3 & Period 4 & Period 5 & Period 6 & Period 7 & Period 8 & Period 9 & Period 10 & Avg. 1-7 \\
\hline 1 & 2.50 & 0.99 & 2.80 & -0.10 & 2.08 & 1.86 & 2.10 & 2.00 & 0.50 & 1.50 & 1.75 \\
\hline 2 & 0.20 & 0.02 & -0.02 & -0.02 & -0.25 & 0.00 & 0.05 & -0.09 & -0.20 & -0.38 & 0.00 \\
\hline 3 & 1.90 & -1.25 & 3.00 & 0.50 & -0.30 & -0.10 & 0.29 & -0.70 & -0.05 & -0.02 & 0.58 \\
\hline 4 & 0.25 & 0.35 & 0.23 & 0.01 & 0.10 & 0.07 & -0.08 & 0.05 & -0.04 & 0.00 & 0.13 \\
\hline 5 & 0.10 & 0.35 & 0.15 & 0.14 & -0.05 & 0.11 & 0.15 & 0.25 & 0.15 & -0.13 & 0.14 \\
\hline 6 & 0.05 & 0.07 & 0.10 & -0.03 & 0.05 & 0.00 & 0.19 & 0.00 & 1.18 & -0.04 & 0.06 \\
\hline 7 & 0.85 & 1.35 & 0.95 & 0.55 & 0.00 & -0.90 & -0.08 & -0.10 & -0.53 & 0.09 & 0.39 \\
\hline 8 & 0.05 & -0.05 & 0.03 & 0.06 & -0.03 & 0.07 & -0.02 & 0.00 & 0.01 & -0.32 & 0.02 \\
\hline 9 & -4.00 & 7.50 & 1.25 & -0.80 & 0.05 & 0.08 & -0.65 & -0.11 & -0.18 & -0.05 & 0.49 \\
\hline 10 & 2.71 & 1.50 & -1.00 & 5.50 & 2.51 & 0.50 & 0.00 & -1.25 & -0.20 & -0.03 & 1.67 \\
\hline 11 & -2.65 & -0.48 & 0.20 & 0.03 & 0.24 & -1.92 & 0.30 & 0.35 & 0.07 & 0.00 & -0.61 \\
\hline 12 & -3.12 & -0.03 & 0.50 & 0.06 & 0.02 & 1.19 & -0.01 & -0.10 & -0.03 & 0.10 & -0.20 \\
\hline Average & -0.10 & 0.86 & 0.68 & 0.49 & 0.37 & 0.08 & 0.19 & 0.03 & 0.06 & 0.06 & 0.37 \\
\hline p-value & 0.304 & 0.085 & 0.010 & 0.122 & 0.206 & 0.271 & 0.176 & 0.624 & 0.641 & 0.722 & 0.051 \\
\hline
\end{tabular}


TABLE 3 Continued

Panel B: Percentage difference between median asset prices: (Untruncated Price - Truncated Price) / Truncated Price

\begin{tabular}{|c|c|c|c|c|c|c|c|c|c|c|c|}
\hline Session & Period 1 & Period 2 & Period 3 & Period 4 & Period 5 & Period 6 & Period 7 & Period 8 & Period 9 & Period 10 & Avg. 1-7 \\
\hline 1 & $33.3 \%$ & $11.0 \%$ & $53.8 \%$ & $-1.3 \%$ & $27.7 \%$ & $25.5 \%$ & $31.1 \%$ & $30.8 \%$ & $12.5 \%$ & $100.0 \%$ & $25.9 \%$ \\
\hline 2 & $10.0 \%$ & $0.8 \%$ & $-0.8 \%$ & $-0.9 \%$ & $-13.5 \%$ & $0.0 \%$ & $5.3 \%$ & $-7.5 \%$ & $-13.3 \%$ & $-19.2 \%$ & $0.1 \%$ \\
\hline 3 & $61.3 \%$ & $-15.9 \%$ & $75.0 \%$ & $14.3 \%$ & $-10.9 \%$ & $-3.7 \%$ & $10.7 \%$ & $-23.3 \%$ & $-3.2 \%$ & $-4.0 \%$ & $18.7 \%$ \\
\hline 4 & $5.9 \%$ & $10.8 \%$ & $8.4 \%$ & $0.4 \%$ & $4.5 \%$ & $5.5 \%$ & $-20.0 \%$ & $12.5 \%$ & $-11.4 \%$ & $0.0 \%$ & $2.2 \%$ \\
\hline 5 & $5.3 \%$ & $25.0 \%$ & $10.0 \%$ & $9.7 \%$ & $-3.2 \%$ & $8.1 \%$ & $12.5 \%$ & $26.3 \%$ & $30.0 \%$ & $-44.8 \%$ & $9.6 \%$ \\
\hline 6 & $1.0 \%$ & $1.4 \%$ & $2.0 \%$ & $-0.6 \%$ & $1.0 \%$ & $0.0 \%$ & $4.0 \%$ & $0.0 \%$ & $51.1 \%$ & $-6.7 \%$ & $1.3 \%$ \\
\hline 7 & $14.0 \%$ & $23.9 \%$ & $14.4 \%$ & $8.5 \%$ & $0.0 \%$ & $-15.0 \%$ & $-1.5 \%$ & $-1.9 \%$ & $-16.6 \%$ & $39.1 \%$ & $6.3 \%$ \\
\hline 8 & $1.3 \%$ & $-1.3 \%$ & $1.0 \%$ & $2.2 \%$ & $-1.3 \%$ & $3.6 \%$ & $-1.6 \%$ & $0.0 \%$ & $0.9 \%$ & $-29.1 \%$ & $0.5 \%$ \\
\hline 9 & $-16.7 \%$ & $1500.0 \%$ & $71.4 \%$ & $-28.6 \%$ & $3.6 \%$ & $9.4 \%$ & $-47.1 \%$ & $-15.7 \%$ & $-37.5 \%$ & $-20.8 \%$ & $213.2 \%$ \\
\hline 10 & $13.6 \%$ & $9.1 \%$ & $-8.3 \%$ & $84.6 \%$ & $22.8 \%$ & $4.5 \%$ & $0.0 \%$ & $-20.2 \%$ & $-8.7 \%$ & $-2.4 \%$ & $18.0 \%$ \\
\hline 11 & $-37.9 \%$ & $-11.7 \%$ & $5.3 \%$ & $0.8 \%$ & $6.0 \%$ & $-49.0 \%$ & $8.8 \%$ & $11.7 \%$ & $4.3 \%$ & $0.0 \%$ & $-11.1 \%$ \\
\hline 12 & $-62.0 \%$ & $-1.1 \%$ & $34.5 \%$ & $4.0 \%$ & $1.2 \%$ & $73.0 \%$ & $-0.6 \%$ & $-6.2 \%$ & $-2.3 \%$ & $22.2 \%$ & $7.0 \%$ \\
\hline Average & $2.4 \%$ & $129.3 \%$ & $22.2 \%$ & $7.8 \%$ & $3.2 \%$ & $5.2 \%$ & $0.1 \%$ & $0.5 \%$ & $0.5 \%$ & $2.9 \%$ & $24.3 \%$ \\
\hline p-value & 0.253 & 0.098 & 0.005 & 0.089 & 0.207 & 0.166 & 0.281 & 0.500 & 0.625 & 0.615 & 0.009 \\
\hline
\end{tabular}


TABLE 4: Statistics Pertaining to the Presence of Bubbles in the MP Markets

The number of positive periods is the number of periods where the median price is greater than the riskneutral value. The number of positive trades is the total number of trades where the price exceeds riskneutral value, and the percent of positive trades is the number of positive trades divided by the total number of transactions. The average median price deviation is the average across periods of the differences between the median price and the risk-neutral value in each period. Average scaled price deviation averages across periods the differences between the median price and the risk neutral value normalized by the risk-neutral value.

\begin{tabular}{cccccc}
\hline Session & Asset & $\begin{array}{c}\text { No. of Positive } \\
\text { Periods }\end{array}$ & $\begin{array}{c}\text { Percent. of } \\
\text { Positive Trades }\end{array}$ & $\begin{array}{c}\text { Average Price } \\
\text { Deviation }\end{array}$ & $\begin{array}{c}\text { Average Scaled } \\
\text { Price Deviation }\end{array}$ \\
\hline 1 & Untruncated & 10 & $96 \%$ & 5.75 & 3.49 \\
1 & Truncated & 10 & $97 \%$ & 4.12 & 2.40 \\
\hline 2 & Untruncated & 2 & $9 \%$ & -0.52 & 0.11 \\
2 & Truncated & 2 & $16 \%$ & -0.45 & 0.24 \\
\hline 3 & Untruncated & 10 & $90 \%$ & 1.29 & 0.59 \\
3 & Truncated & 9 & $87 \%$ & 0.97 & 0.53 \\
\hline 4 & Untruncated & 1 & $23 \%$ & -0.35 & -0.30 \\
4 & Truncated & 1 & $9 \%$ & -0.44 & -0.32 \\
\hline 5 & Untruncated & 0 & $9 \%$ & -0.87 & -0.35 \\
5 & Truncated & 0 & $5 \%$ & -0.99 & -0.39 \\
\hline 6 & Untruncated & 10 & $100 \%$ & 2.15 & 1.31 \\
6 & Truncated & 10 & $100 \%$ & 1.99 & 1.16 \\
\hline 7 & Untruncated & 9 & $89 \%$ & 3.11 & 1.54 \\
7 & Truncated & 9 & $85 \%$ & 2.89 & 1.53 \\
\hline 8 & Untruncated & 4 & $37 \%$ & 0.01 & 0.10 \\
8 & Truncated & 3 & $38 \%$ & 0.03 & 0.17 \\
\hline 9 & Untruncated & 2 & $29 \%$ & 1.52 & 0.17 \\
9 & Truncated & 1 & $24 \%$ & 1.21 & 0.13 \\
\hline 10 & Untruncated & 10 & $100 \%$ & 8.50 & 3.58 \\
10 & Truncated & 10 & $92 \%$ & 7.47 & 3.31 \\
\hline 11 & Untruncated & 9 & $91 \%$ & 0.99 & 0.72 \\
11 & Truncated & 10 & $95 \%$ & 1.38 & 0.82 \\
\hline 12 & Untruncated & 4 & $33 \%$ & -0.47 & -0.04 \\
12 & Truncated & 4 & $30 \%$ & -0.32 & -0.05 \\
\hline
\end{tabular}


TABLE 5: Different Dichotomizations of Bubble vs. No-Bubble Sessions

This table shows which sessions fall into bubble and no-bubble categories using the four dichotomizations discussed in the paper.

\begin{tabular}{ccc}
\hline Dichotomization & Bubble Sessions & No-Bubble Sessions \\
\hline A & $1,3,6,7,10,11$ & $2,4,5,8,9,12$ \\
\hline B & $1,6,7,10$ & $2,4,5,8,12$ \\
\hline C & $1,6,7,10$ & $2,4,5,8,9,12$ \\
\hline
\end{tabular}




\section{TABLE 6: Price Differences and Bubbles}

The average price difference is the median untruncated price - median truncated price first averaged across periods one to seven of a session, and then averaged across sessions classified as either bubble or nobubble. The average percentage price difference is the median (untruncated price - median truncated price)/truncated price first averaged across periods one to seven of a session, and then averaged across sessions classified as either bubble or no-bubble. Three methods of classifying sessions are used. The Pooled $t \mathrm{p}$-value is the $\mathrm{p}$-value from a one tailed pooled $\mathrm{t}$ test with the null that the price difference in the bubble sessions equals the price difference in the no bubble sessions. The Wilcoxon Rank Sum p-value is the p-value from the corresponding one-tailed non-parametric hypothesis test with the same null.

\begin{tabular}{|c|c|c|c|}
\hline Dichotomization A & Bubble Sessions & No Bubble Sessions & \\
\hline Average Price Difference & 0.64 & -0.10 & \\
\hline Pooled t p-value & & & 0.046 \\
\hline Wilcoxon Rank Sum p-value & & & 0.047 \\
\hline Average Percentage Price Difference & $9.90 \%$ & $0.72 \%$ & \\
\hline Pooled t p-value & & & 0.098 \\
\hline Wilcoxon Rank Sum p-value & & & 0.120 \\
\hline Number of Sessions & 6 & 6 & \\
\hline Dichotomization B & Bubble Sessions & No Bubble Sessions & \\
\hline Average Price Difference & 0.97 & 0.02 & \\
\hline Pooled t p-value & & & 0.022 \\
\hline Wilcoxon Rank Sum p-value & & & 0.032 \\
\hline Average Percentage Price Difference & $12.88 \%$ & $3.88 \%$ & \\
\hline Pooled t p-value & & & 0.068 \\
\hline Wilcoxon Rank Sum p-value & & & 0.143 \\
\hline Number of Sessions & 4 & 5 & \\
\hline Dichotomization C & Bubble Sessions & No Bubble Sessions & \\
\hline Average Price Difference & 0.97 & -0.10 & \\
\hline Pooled t p-value & & & 0.011 \\
\hline Wilcoxon Rank Sum p-value & & & 0.019 \\
\hline Average Percentage Price Difference & $12.88 \%$ & $0.72 \%$ & \\
\hline Pooled t p-value & & & 0.044 \\
\hline Wilcoxon Rank Sum p-value & & & 0.086 \\
\hline Number of Sessions & 4 & 6 & \\
\hline
\end{tabular}




\section{TABLE 7: Comparing Multi-period Prices and Single Period Prices}

Each session consists of two single period markets and a multi-period market, SP-5, SP-8 and MP-10. (MP-10)-(SP-8) is the difference between the median price in the third period of the MP-10 market and the SP-8 market median price. Both of these are prices of the asset with eight remaining dividend drawings. (MP-10)-(SP-5) is the difference between the median price in the sixth period of the MP-10 market and the SP-5 market median price. Both of these are prices of the asset with five remaining dividend drawings. The paired $t \mathrm{p}$-value is the $\mathrm{p}$ value from a one-tailed paired t-test with the null hypothesis that the price in the MP market equals the price in the SP market. The Wilcoxon p-value is the result of the corresponding one-tailed Wilcoxon Signed Rank test with the same null hypothesis

\begin{tabular}{ccccc}
\hline Session & $\begin{array}{c}\text { (MP-10)-(SP-8) } \\
\text { Untruncated }\end{array}$ & $\begin{array}{c}\text { (MP-10)-(SP-8) } \\
\text { Truncated }\end{array}$ & $\begin{array}{c}\text { (MP-10)-(SP-5) } \\
\text { Untruncated }\end{array}$ & $\begin{array}{c}\text { (MP-10)-(SP-5) } \\
\text { Truncated }\end{array}$ \\
\hline 1 & $\$ 0.25$ & $\$ 0.20$ & $\$ 0.66$ & $-\$ 1.20$ \\
2 & -0.50 & -0.20 & 0.79 & 0.73 \\
3 & 6.33 & 3.40 & 1.35 & 0.90 \\
4 & 2.65 & 2.45 & 1.05 & 0.98 \\
5 & -1.85 & -2.00 & -0.22 & -0.65 \\
6 & 0.18 & -0.13 & 0.85 & -0.15 \\
7 & 6.40 & 5.60 & -0.90 & -2.00 \\
8 & -0.06 & -1.19 & 1.43 & 1.68 \\
9 & 2.74 & 1.50 & 0.77 & 0.65 \\
10 & 8.03 & 8.06 & 10.50 & 9.91 \\
11 & -6.02 & -0.73 & -4.00 & -1.59 \\
12 & 0.70 & 0.35 & -1.43 & -2.12 \\
\hline All Sessions & 1.57 & 1.44 & 0.90 & 0.60 \\
\hline Paired t p-value & .097 & .061 & .188 & .266 \\
\hline Wilcoxon p-value & .076 & .105 & .196 & .508 \\
\hline
\end{tabular}




\section{TABLE 8: Comparing Multi-period Prices and Single Period Prices}

Each session consists of two single period markets and a multi-period market, SP-5, SP-8 and MP-10. The sessions were classified as Bubble (B) or No Bubble (NB) according to three dichotomizations. (MP-10)-(SP-8) is the difference between the median price in the third period of the MP-10 market and the SP-8 market median price. Both of these are prices of the asset with eight remaining dividend drawings. (MP-10)-(SP-5) is the difference between the median price in the sixth period of the MP-10 market and the SP- 5 market median price. Both of these are prices of the asset with five remaining dividend drawings. The pooled $\mathrm{t}$ p-value is the result of a one-tailed hypothesis test with a null that the MP-SP in bubble sessions is the same ad the MP-SP in the no-bubble sessions. The Wilcoxon Rank Sum p-value corresponds to one-tailed non-parametric tests with the same null hypothesis.

\begin{tabular}{rcccc}
\hline & $\begin{array}{c}\text { MP10-SP8 } \\
\text { Bubble Sessions }\end{array}$ & $\begin{array}{c}\text { MP10-SP8 } \\
\text { No Bubble Sessions }\end{array}$ & $\begin{array}{c}\text { MP10-SP5 } \\
\text { Bubble Sessions }\end{array}$ & $\begin{array}{c}\text { MP10-SP5 } \\
\text { No Bubble Sessions }\end{array}$ \\
\hline Dichotomization A & & & & \\
Untruncated Asset & 2.53 & 0.61 & 1.41 & 0.40 \\
Truncated Asset & 2.57 & 0.15 & 0.98 & 0.21 \\
Pooled t p-value & 0.213 & 0.070 & 0.315 & 0.273 \\
Wilcoxon Rank Sum p-value & 0.197 & 0.120 & 0.531 & 0.468 \\
Number of Sessions & 6 & 6 & 6 & 6 \\
\hline Dichotomization B & & & & 0.32 \\
Untruncated Asset & 3.72 & 0.19 & 2.78 & 0.12 \\
Truncated Asset & 3.43 & -0.12 & 1.64 & 0.286 \\
Pooled t p-value & 0.060 & 0.058 & 0.167 & 0.452 \\
Number of Sessions & 0.095 & 0.095 & 0.452 & 5 \\
Wilcoxon Sum p-value & 4 & 5 & 4 & 0.40 \\
\hline Dichotomization C & & & & 0.21 \\
Untruncated Asset & 3.72 & 0.61 & 1.64 & 0.277 \\
Truncated Asset & 3.43 & 0.15 & 0.148 & 0.381 \\
Pooled t p-value & 0.067 & 0.054 & 0.457 & 6 \\
Nunk Sum p-value & 0.129 & 0.129 & 4 & \\
\hline
\end{tabular}




\section{FIGURE 1: Price Paths for Multi-period Markets that Exhibit Bubble Pattern}

under Dichotomization A (Sessions 1, 3, 6, 7, 10, and 11)

These price paths show median prices (averaged over assets A and B) each period during sessions 1, 3, 6, 7, 10 and 11, which are categorized as bubble sessions using Dichotomization A. When no trading occurs, the average of the terminal bid and ask is used. Risk-neutral price path (IV) is provided as referent.

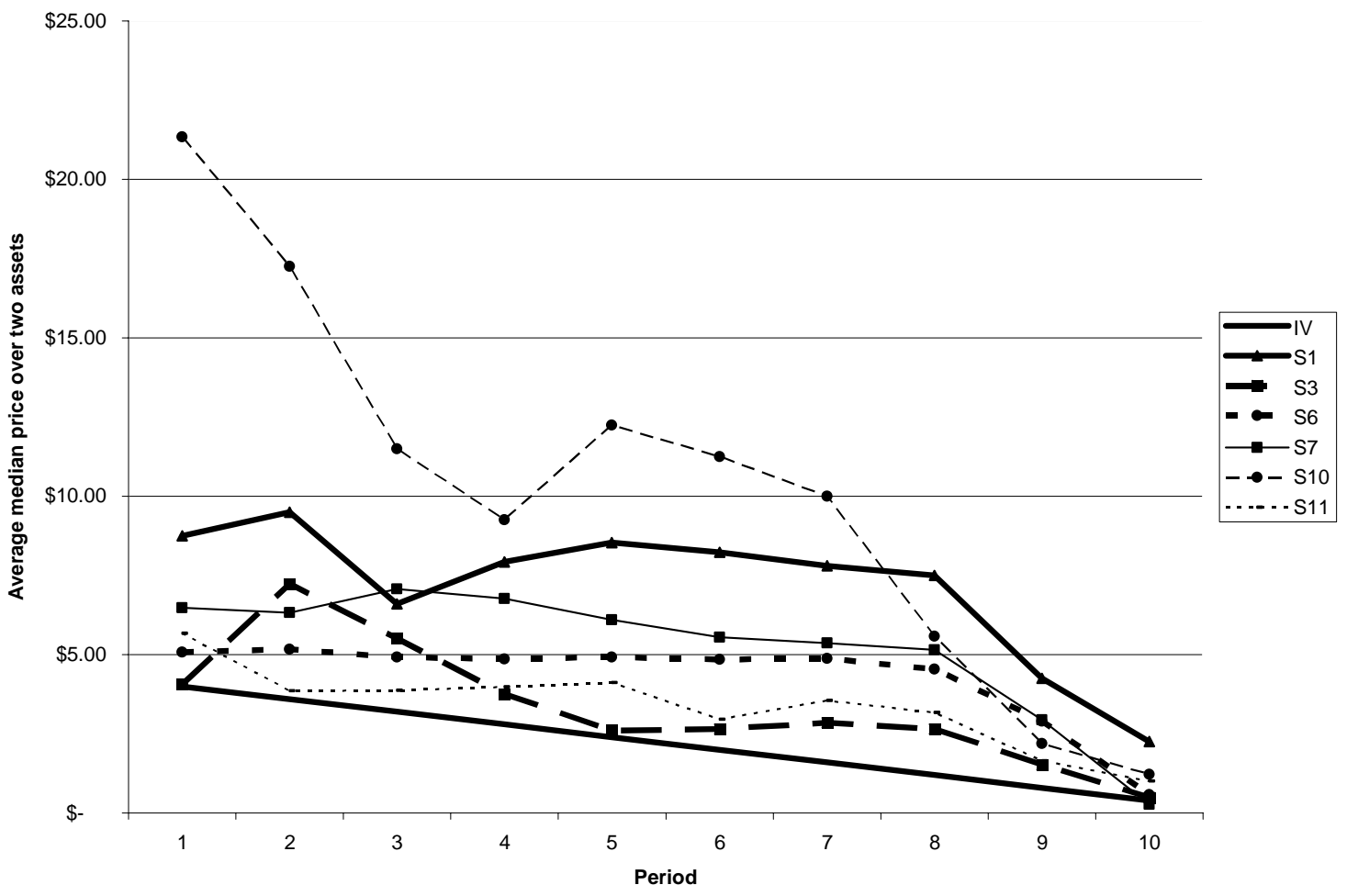


FIGURE 2

Price Paths for Multi-period Markets that Do Not Exhibit Bubble Pattern under Dichotomization 1 (Sessions 2, 4, 5, 8, 9, and 12)

These price paths show median prices (averaged over assets A and B) each period during sessions 2, 4, 5, 8, 9, and 12, which are categorized as no-bubble sessions using Dichotomization A. When no trading occurs, the average of the terminal bid and ask is used. Risk-neutral price path (IV) is provided as referent.

\section{Panel A: Scale same as for Figure 1}

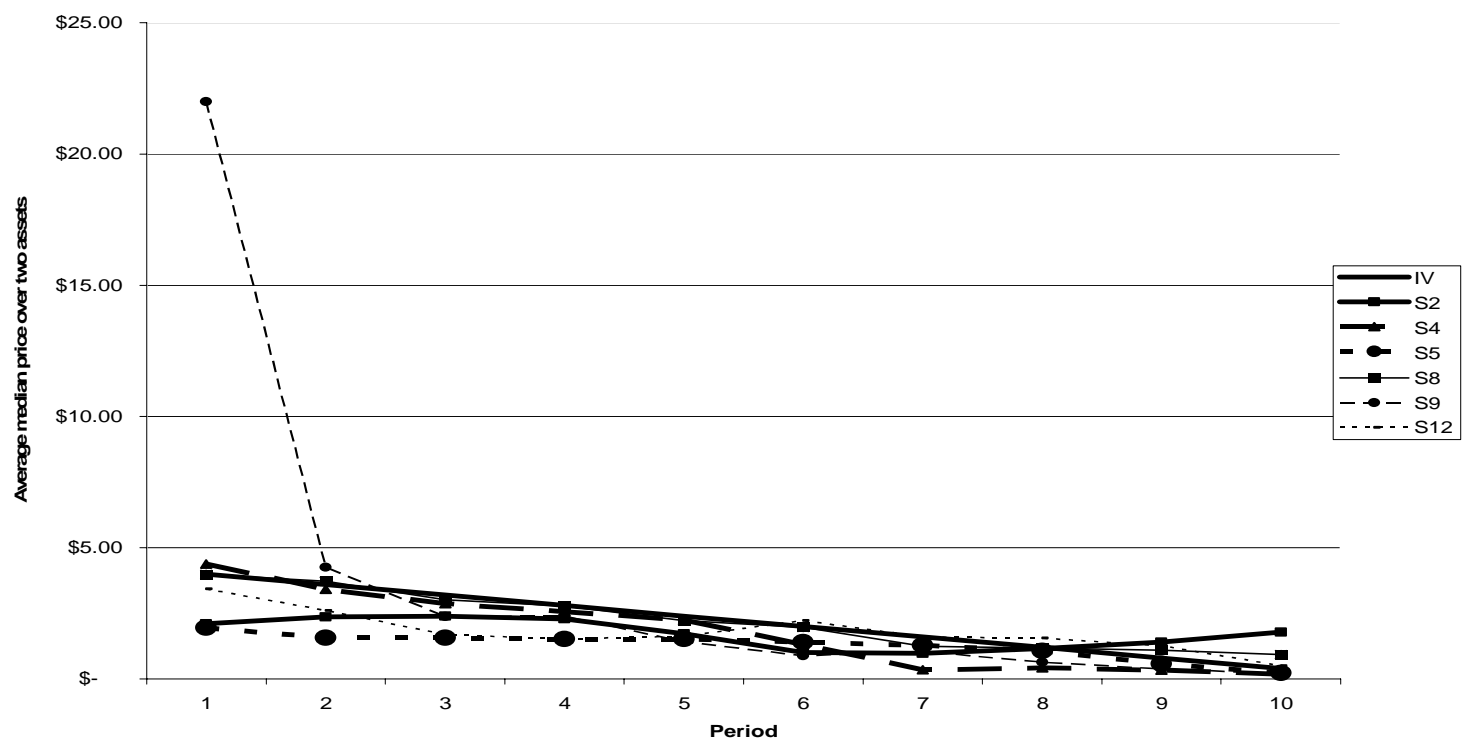

Panel B: Rescaled to show differences more clearly

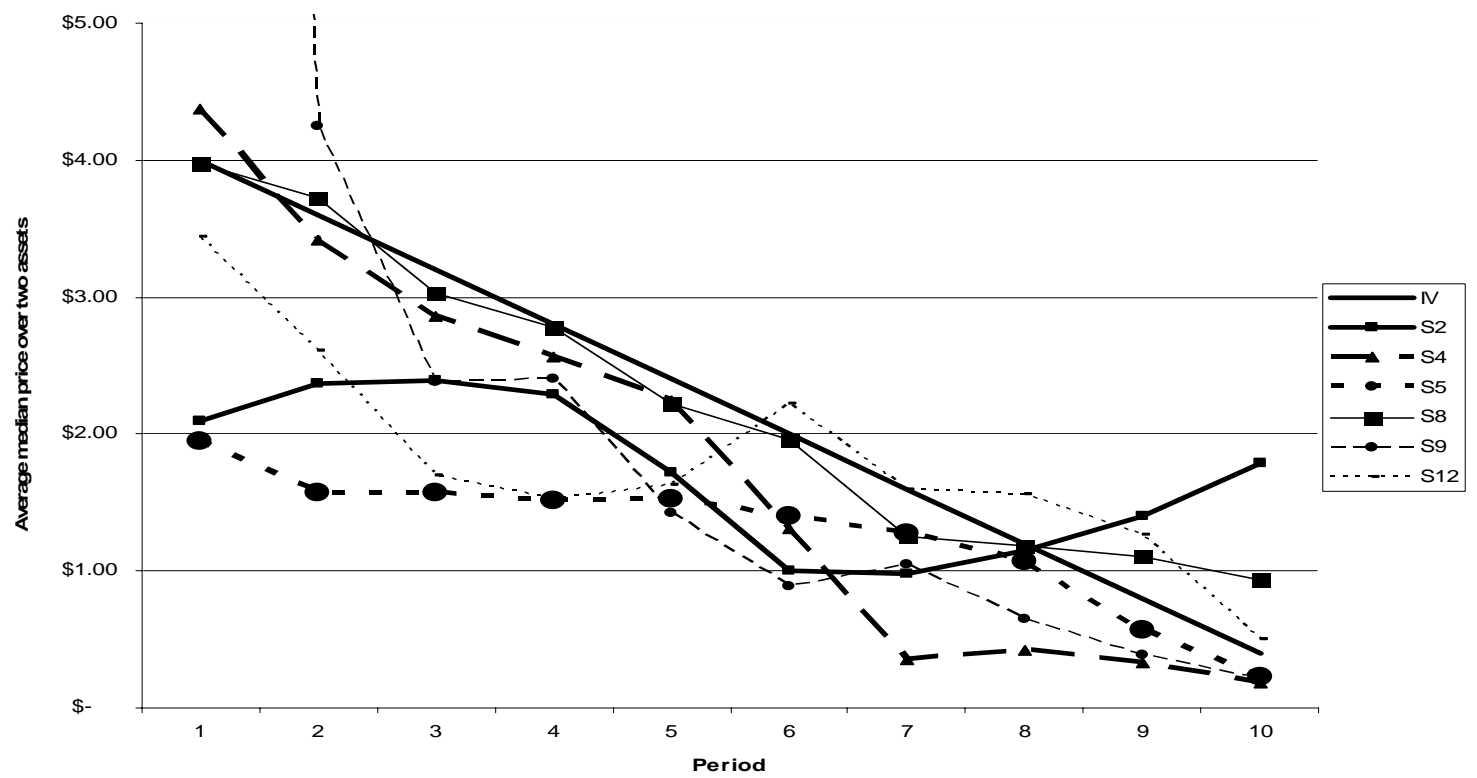




\section{Appendix 1
INSTRUCTIONS FOR TRADING SESSIONS}

\section{Introduction}

1.a. The nature of the session. The experimental session that you are participating in today is concerned with the economics of market decision-making. We are going to simulate a market environment in which you will buy and sell shares of two different stocks. Based on your decisions you will be able to generate profits. These profits will be paid to you in cash at the conclusion of this experiment.

1.b. Three trials. Trading will occur during three different and distinct trials. One trial will take place over a sequence of 10 periods. Two other trials will take place over a single period. In the first three sections of these Instructions we will focus on the 10-period trial. In section 4 we will highlight the few differences between the 10-period trial and the two single-period trials. Your total earnings will be the sum of your earnings during these three trials plus a $\$ 15$ attendance fee. If your cumulative earnings are negative you will lose this attendance fee dollar for dollar. The order in which these three trials will be conducted will be revealed as the market simulation progresses.

1.c. What materials should you have? In addition to these instructions, please make sure that you have received an "Introduction to the Session" and a consent form (which you should immediately read and sign if you agree to participate). Please refer to these materials while we go through the instructions with you. In addition, you can use a calculator and any scrap paper and writing utensils that you like.

\section{Market Setup and General Trading Instructions}

2.a. Periods. Trading will be conducted using the computerized Financial Trading System. There will be a series of 10 periods. Each period lasts five minutes. An experimenter will announce the beginning and end of each period. Your trading screen will continuously keep track of the time remaining (in seconds) in each period. 
2.b. Getting started. Your computer has already been started up and you have been logged in under the name 'PCXX' where ' $\mathrm{XX}$ ' is the number you have been assigned. As a result, your anonymity is ensured.

2.c. Endowment. At the beginning of the first period, every trader will be provided with the same endowment, which consists of $\$ 40$ in cash and 2 shares each of stock $A$ and stock $\boldsymbol{B}$. This endowment will be shown on your trading screen before trading commences. Your compensation for participating in this experiment will depend on how well you do relative to this starting endowment. Note that at the conclusion of trading in this trial you will be required to return the endowment of $\$ 40$.

2.d. Trading. When trading starts in each period, you may sell part or all of your holdings of shares. You may alternatively use your cash endowment to purchase more shares. You may also decide to do no trading and hold on to the shares that you have at the start of the period. The procedure that you need to use if you wish to conduct a trade is explained in the 'Market Organization and Trading Rules' section below.

2.e. Selling and buying shares. Sales of your share holdings increase your cash balance by the amount of the sale price. Similarly, purchases reduce your cash balance by the amount of the purchase price. Thus, you can gain or lose money on the purchase and sale of shares. The trading system will automatically update your cash balance and share holdings to reflect your purchases and/or sales of shares.

2.f. Tracking prices. By double-clicking on the stock name in the Book Window, you will be shown a graph that tracks the bid/ask/transaction price history for the relevant security over the current period. The bid price will be displayed in red, the ask price in blue, and the transaction price in yellow. This graph will refresh itself at the beginning of each period. At the end of each period an experimenter will verbally announce the closing price (i.e., last trade) for each stock. In addition he will write these numbers on the whiteboard at the front. 
2.g. Dividends. At the end of each period, stock $A$ and stock B will pay dividends. An experimenter will announce and write these values on the whiteboard. For each stock, the amount of the dividend per share can be $\$ \odot$ or $\$ 20$. These two possible values will be randomly determined by blindly drawing a chip from a plastic jar. Additional details concerning the possible dividends are given in the 'Dividends' section below.

2.h. Calculating dividends. At the end of each period, the actual dividend amount for each stock will be revealed on your trading screen. The total dividends that you will receive from each stock in a period are computed by multiplying the dividend per share for that stock by the number of shares of the stock that you hold at the end of the period. Suppose, for example, that you hold 2 shares of stock $A$ at the end of period 1 . If for that period the dividend per share is $\$ 20.00$, then your total dividends from stock $A$ in the period would be $2 \times \$ 20.00=\$ 40.00$. This number will be added automatically by the trading system to your cash balance at the end of each period. If the dividend per share is $\$ \odot$, your cash balance will not change due to dividends.

2.i. Source of trading profits. As a result, your trading profits in a given period come from two sources - from (i) dividends on all shares you hold at the end of the period; and (ii) gains and losses from purchasing and selling shares.

2.j. Carry forward. The cash balance and shares that you have at the end of one period will be carried forward to the next period, during which you are again free to trade the shares. Notice that if you choose to hold a share over several periods, then you will be entitled to the random dividend paid during each of those periods. 
2.k. Final period. At the end of the final period (period 10), the shares you hold will pay their final dividends and then cease to exist. Your trading screen will display your final cash balance. Your final earnings will therefore be equal to your final cash balance (shown on your screen at the end) minus the original cash endowment of $\$ 40$. You will be paid this amount in cash immediately after the experiment ends. Note that if your final cash balance is less than the original cash endowment, you will earn nothing from this trial. Also, note that, because you are also originally endowed with two shares of each stock, which you can sell for cash, or hold on to for their dividends, your final cash balance is expected to be greater than the original $\$ 40$.

\section{Dividends}

3.a. Dividend determination. For each stock, there are two possible dividends: $\$ \odot$ and $\$ 20$. At the end of each period, the dividends for stocks $A$ and $B$ are randomly determined, subject to the following constraint. If stock $B$ pays three dividends of $\$ 20$, the dividends for stock $B$ will be $\$ 0$ in all remaining periods. Otherwise, the amount of the dividend for each stock is determined by blindly drawing a chip from a plastic jar. This drawing is done separately for each stock (first for A and then for B), and the first chip drawn (the one for $A$ ) will be replaced before the second drawing (for B) occurs. The jar contains 100 chips; 98 are red; and the other 2 are also red but have been marked with black circles on each side. That is to say, of these 100 chips, 98 are red and two are marked black. For each drawing, the experimenter will ask a participant to blindly draw a chip from the jar. (We will give all

subjects several opportunities.) If a red chip is drawn the dividend is $\$ \odot$ and if a black chip is drawn the dividend is $\$ 20$.

3.b. Expected dividends. One can easily calculate that the expected value of stock A's dividend per period is $\$ 0.40$. The expected value of Stock $B^{\prime}$ 's dividend per period is also $\$ 0.40$, if the stock is still paying dividends (that is, if it has paid out less than 3 dividends in prior periods). At the end of each period, an experimenter will announce the expected total remaining dividends for the two stocks and the maximum total remaining dividends. Notice that because Stock $B$ pays a maximum of 3 dividends, the expected total dividends for $B$ are always less than or equal to the maximum total remaining dividends for $A$. 
3.c. Dividend independence. As stated above, the amount of the dividend for each stock in a given period is determined by separate draws from the jar. After drawing a chip, the chip is always returned to the jar before any additional draws. Thus, the dividend for each stock is determined independently of both past amounts and independently of the dividend for the other stock.

\section{Two single-period markets}

4.a. Single-period but with same endowment. While the 10period trial occurs over 10 periods with stocks and cash carried over between periods, the single-period trials occur over only one period. (Periods continue to be 5 minutes in duration.) In the case of both single-period trials, the endowment is identical to the 10-period endowment. That is, you begin with $\$ 40$ (which must be returned) and two shares of Stock A and two shares of Stock B.

4.b. Dividends - Multiple draws. Dividend determination will occur in a similar fashion with students drawing chips. There is one essential difference. In one of these singleperiod trials, the one and only dividend for each stock will be determined by drawing with replacement five chips from the jar. In the other, the one and only dividend for each stock will be determined by drawing with replacement eight chips from the jar. Each black chip drawn will be worth $\$ 20$. For example, using stock $A$, if for the 8-chip draw 4 black chips are drawn, the dividend is $\$ 80 /$ share. It is important to note that, just as in the case of the 10-period trial, a maximum of three \$20 draws are permitted for stock B. This means that, using stock B now, as soon as 3 black chips are drawn, no more draws will occur, and the dividend is $\$ 60$.

\section{Market Organization and Trading Rules}

5.a. Possible actions. If you wish to conduct a trade, you can do so by taking one or more of the following four actions: 1/place a bid; 2/place an ask; 3/buy; and 4/sell. 
5.b. Placing orders. To take these actions, you must utilize your main FTS Trader window. When you look at it you will see that there are four sub-windows. First note that you only input information (orders) into the top middle sub-window which we call the 'Order Window.' Also important is the lower sub-window which we call the 'Book Window.' To place an order you must specify which stock the order is for. You do this by first clicking on the name of the stock (in the Book Window) in which you wish to conduct a trade. You will see the name of the stock is then indicated above the order Window after you have clicked on it. There are two cells that now potentially should be filled in. First for a bid or ask the price cell should be filled in. second, for all orders (bids, asks, buys and sells) a quantity of ' 1 ' needs to be filled in. This is because in this experiment all orders must be for one share.

5.c. Placing a bid. By placing a bid, you inform the market that you wish to purchase a share of a specified stock at a specified unit price. For example, if you wish to buy a share at a price of $\$ x x . x x$, then you will enter:

$$
x x \cdot x x
$$

and click on 'Bid' in your order Window. (You must also have first selected a quantity of '1.') You are, however, prohibited from entering a bid whose purchase price exceeds your current cash balance.

5.d. Display of best bid. The Book Window will display only the bid order with the highest price. Bettered bids are replaced and cease to exist. To see the identity of the trader posting the best bid (you certainly will want to know if it is your order), you can double-click on the stock name. Doing so reveals a new window, which includes a graph that shows the evolution of bids, asks and transaction prices during the period.

5.e. Order cancellation. To cancel your bid, click on 'Clear Bids.' of course you cannot cancel another trader's bid. 
5.f. Selling shares. When you observe the highest bid for a stock and if you have a share of that stock to sell, you are free to accept or not accept that highest bid. To accept it, you have to enter the number of shares, which you must set at '1,' in the Order Window and click on 'Sell.' You should not specify a price. If you do so the sale will not occur. After you have put in the order your sale will be immediately executed at the bid price. You are prohibited from submitting a sell order if you do not hold the security.

5.g. Placing an ask. On the other hand, if you wish to sell but are not satisfied with the observed bid price, you can place an ask into the trading system. Once again a price has to be specified. Also, once again, the number of shares must be set at '1.' After these things are done you must click on 'Ask' in your order Window. You are prohibited from submitting an ask order if you do not own a share. Again, to delete your ask, you can click on 'Clear Asks.'

5.h. Buying shares. If you wish to buy at the lowest ask price, you have to enter ' 1 ' and click on 'Buy' in the order Window. Again note that you should not specify the price. The buy order will be immediately executed at the ask price. Again, traders are prohibited from buying more shares than they have the cash balance for.

5.i. Updating of cash and share holdings. After a trade is executed, the trading system will immediately update your cash balance and share holdings and display them on the screen. At the end of each period, your screen will also show your cash balance and share holdings, which will then be carried forward to the beginning of the following period (assuming there is more than one period in the trial).

5.j. Final period. At the end of the final period - period 10 for one trial and period 1 for two other trials, the trading system will display the final cash balance and also calculate your earnings. Your trading profit for the trial in question is calculated as the cash balance you see on your screen minus the $\$ 40$ initial cash endowment. (This could be a negative number, and if the sum of your earnings from all three trials is negative, your attendance fee will be reduced dollar for dollar.) 
TRIAL - KEY FACTS

NUMBER OF PERIODS: 10

CASH ENDOWMENT: $\$ 40$

ENDOWMENT OF A SHARES: 2

ENDOWMENT OF B SHARES: 2

DIVIDENDS: AFTER EACH PERIOD A SINGLE DRAW OCCURS FOR EACH STOCK. A BLACK CHIP PAYS OUT A \$20 DIVIDEND; A RED CHIP PAYS OUT NO DIVIDEND. RECALL THERE ARE 98 RED CHIPS AND 2 BLACK.

NOTE: A SHARES CAN RECEIVE AS MANY $\$ 20$ DIVIDENDS AS THERE ARE PERIODS. B SHARES CAN AT MOST RECEIVE THREE \$2O DIVIDENDS. 
TRIAL - KEY FACTS

NUMBER OF PERIODS: 1

CASH ENDOWMENT: $\$ 40$

ENDOWMENT OF A SHARES: 2

ENDOWMENT OF B SHARES: 2

DIVIDENDS: AFTER THE ONLY PERIOD OF THE TRIAL, 8 DRAWS WILL BE DONE FOR EACH STOCK. EACH BLACK CHIP PAYS OUT A \$2O DIVIDEND; EACH RED CHIP PAYS OUT NO DIVIDEND. RECALL THERE ARE 98 RED CHIPS AND 2 BLACK.

NOTE: A SHARES CAN RECEIVE AS MANY \$20 DIVIDENDS AS THERE ARE DRAWS, SO THE MAXIMUM DIVIDEND FOR A IS \$160. B SHARES CAN AT MOST RECEIVE THREE \$20 DIVIDENDS, OR \$60. 
TRIAL - KEY FACTS

NUMBER OF PERIODS: 1

CASH ENDOWMENT: $\$ 40$

ENDOWMENT OF A SHARES: 2

ENDOWMENT OF B SHARES: 2

DIVIDENDS: AFTER THE ONLY PERIOD OF THE TRIAL, 5 DRAWS WILL BE DONE FOR EACH STOCK. EACH BLACK CHIP PAYS OUT A \$2O DIVIDEND; EACH RED CHIP PAYS OUT NO DIVIDEND. RECALL THERE ARE 98 RED CHIPS AND 2 BLACK.

NOTE: A SHARES CAN RECEIVE AS MANY \$20 DIVIDENDS AS THERE ARE DRAWS, SO THE MAXIMUM DIVIDEND FOR A IS \$100. B SHARES CAN AT MOST RECEIVE THREE \$20 DIVIDENDS, OR \$60. 